\title{
Assessment in the LMD System: Challenges and Expectations
}

\author{
Aissa Hanifi \\ Department of English, Djillali Liabess University, Sidi Bel ABBES, Algeria \\ Email address: \\ aissahanifi800@yahoo.com \\ To cite this article: \\ Aissa Hanifi. Assessment in the LMD System: Challenges and Expectations. International Journal of Secondary Education. \\ Vol. 6, No. 1, 2018, pp. 8-15. doi: 10.11648/j.ijsedu.20180601.13
}

Received: December 19, 2017; Accepted: December 29, 2017; Published: January 31, 2018

\begin{abstract}
Although decision makers are still uncertain about the efficacy of the incorporation of the LMD (License-MasterDoctorate) system in the different Algerian universities' institutions, it should be admitted that the applicability of such a new system in the university has become a current actual fact whether at the level of the training course syllabus or at the other sphere of the other administrative acts and planning. In fact it is under this scope that the present paper shed light on one important factor in the teaching -learning process which is evaluation and assessment in the LMD system from a purely student's perspective. The aim was to depict the students' views and attitudes towards the whole process and criteria of evaluation being set and put for them under the new LMD system. It should be known that students are assessed and given grades throughout the semester (ongoing assessment) and at the end of each semester (final exam). The final grade is based on both grades using a weighting scale. A wide range of assessments methods are used including examinations, quizzes, homework, oral presentations and essays. The online interviews and questionnaires with the group of twenty one students from Chlef University raised our attention to one serious matter which is that of the fact that some students still ignore a lot on the scale and grid of evaluation of the current LMD system with regard to the different modules' set credits for instance. Besides, some students admitted that their keen interest for grades worked negatively on developing their learning skills and knowledge development. However, the students showed their praise and satisfaction for the new way of evaluating the examinee's performance which is based on the combination of the coursework assignments and sit-down exams.
\end{abstract}

Keywords: LMD System, Assessment, Evaluation, Exams

\section{Introduction}

The LMD system was launched in the Algerian universities in the academic year 2003-2004. After about a decade of implementation, it is useful to evaluate some prominent points of this system. In addition to some obstacles that prevented the fast success and efficiency of the LMD system such as the lack of human and material resources, the big size of the groups and the number of groups per module, the new implemented system also raised the matter of assessment as another debatable issue for both teachers and learners. The present paper will shed light on one type of assessment which is summative assessment since it is liable to be measured and the one which has a direct relation with the students' tests, scores and grades. We shall depict the students' views, attitudes and expectations of the assessment related aspects in the LMD system. This is to be carried through a structured questionnaire to a group of LMD students at Chlef university but let us first proceed by some definitions and key concepts related to the topic. As a matter of fact, the introduction of the LMD system in the Algerian universities came as a necessary step to cope with the international requirements of what is happening in the field of education and world economic and technological innovation and progress. It's implementation was to offer the Algerian students greater chance for more flexibility in their programs of study and facilitate their mobility task at the national and international level. Hence; the LMD aims at bridging the gap between book knowledge and the job market demands. Currently, in Algeria, the system is in the use phase since most of the Algerian universities have adopted the LMD system. Indeed, the LMD is designed so that all system components, including teachers and students have become involved in training and are no more spectators 
as in the "classic" system: the teacher has the opportunity to offer training courses tailored to the available resources and skills based on a pedagogical team and the student has the opportunity to choose the path that suits him. As being the core element in any new adopted system or syllabus, one cannot neglect the learners' own perception of the matter of bringing their own views before the community practitioners in the framework of any newly incorporated system. More importantly, no one can deny the degree of the assessment importance in the in the students' learning life career. Because it occupies such an important part of the students' interest, the teacher is supposed to play the student's guide to the challenges of the assessment. Indeed, instead of having an adversarial relationship, teacher and student are allies. Nevertheless, the current assessment fact in most of our universities still reoccurs as a machine-score that displays grades via one shot tests that do not give real chance of selfcorrection and feedback process for the students; a chance that could help them for more refinement and self improvement.

\section{The LMD System: An Overview}

The new higher education reform also known as the LMD (License-Master-Doctorate) system has been gradually being introduced in our country since 2003-2004. The LMD system came as a natural process to technological breakthroughs, complex international relations and overlapping of economic interests in the new millennium. The implementation of the LMD system's aim in the Algerian Universities is to offer students increased flexibility in their programs of study, greater autonomy in their professional career development and more facilities in their mobility at the national and international level.

\section{LMD Objectives}

The LMD system main objective is to bridge the gap between the gained knowledge at university sphere and the job market demands. Besides, the new reform system aims For instance, at improving both of the quality of the university education It also aimed at the development of academic training vocationally and promoting the staff and students' mobility. Finally, One ultimate objective of the LMD system is to restructure of the higher education institutions and promote practical knowledge. Yet, this would not be achieved without adopting a credit system known as the European Credit Systems (ELTS) as a first step in the process of the LMD system implementation.

With the application of the new system, new keywords have emerged:

-The Semester:

The semester is the period of time necessary to complete an actual course of study during an academic year. In the new structure, the academic year is divided into two academic semesters. A semester counts 16 weeks of study and assessment, comprises 4 modules in average and includes at least 360 hours of study.

-The Module:

The module is the basic unit of university education assigned in one semester. It consists of 1 to 2 coherent and autonomous disciplinary elements allowing a smooth assessment of learning outcomes. Each module has a minimum of 75 hours of study (or 20 to 25 days of field work). In a modular program, courses can be taught in the form of theoretical courses and/or directed works and/or practical works. A module is validated after student's success in continuous assessment or catch-up session.

-Validation:

The assessment of knowledge, skills and competencies are the key cornerstone of the new educational system. In the LMD architecture, the assessment of student's acquisition and learning Is semestrial and not annual. This mode of evaluation is more rational on the educational level, since it gives more emphasis to the interactive relationship during the course rather than the simple exercise of memory. Such a method of assessment equips the student with the required tools since it is organised in a wide range of exams namely tests, presentations reports...... etc in addition to a possible catch up test. In order to progress in his university studies, the student should validate modules. A module is validated if its global mark is superior or equal to 10 out of 20 .

A course is validated if: - All its modules are validated, All its semesters are validated A validated course gives right to acquisition of the corresponding graduate diploma.

With regard to Chlef University, the LMD system was implemented in the English department in the academic year 2009-2010. Just like in some other universities who has recently adopted the LMD system, the implementation of that new reform system in the Chlef University and in the English department in particular has faced and still facing some obstacles that may look similar to that of the "classical system" when referring to a recently opted English department like that in Chlef University. The lack of human resources, the lack of training for the current teaching staff on the LMD system instructional key aspects and the big size of the groups are among the main problems that emerge as real obstacles in the path of the success of any newly adopted reform system such as the LMD system.

\section{Classroom Assessment}

Assessment is one important teaching element in the teaching process since it is about evaluating how much learners have acquired. Classroom Assessment is the observation of students in the process of learning, the collection of frequent feedback on students' learning, and the design of modest classroom experiments that provide information on how students learn and how students respond to particular teaching approaches. According to Grant [1] Learning cannot take place without criterion-referenced assessment, no matter how good the teaching is. Successful learning depends upon adjustment in response to feedback. Classroom assessment helps individual college teachers 
obtain useful feedback on what, how much, and how well their students are learning. Faculty can then use this information to refocus their teaching to help students make their learning more efficient and more effective.

A conspicuous ambiguity often emerges when coming to draw a distinction between assessment and evaluation. We find it necessary to make matters rather clear right from the beginning for most readers who want to know the difference between the two key concept so that that we can proceed tackling the idea of assessment; the core point of our study, on a plain foundation.

\section{Assessment}

It should be mentioned that the term assessment takes its roots from the Latin word 'assidere' which means to sit beside to make calculations. Brown [2] defines assessment as "... an ongoing process that encompasses a much wider domain". Whenever a student responds to a question offers a comment or tries out a new word or structure, the teacher subconsciously makes an assessment of the student performance. Hence, assessment is feedback from the student to the instructor about the student's learning. Brown and knight [3] put more emphasis on the students' behaviour diagnosis when they stated, "Assessment is at the heart of the student experience"

\section{Evaluation}

Evaluation uses methods and measures to judge student learning and understanding of the material for purposes of grading and reporting. Evaluation is feedback from the instructor to the student about the student's learning. By definition; evaluation is about attributing a value to test takers' work. According to Lynch [4], evaluation refers to a systematic attempt to gather information in order to make judgments or decisions. Evaluation is just as important as assessment in the learning process. According to Davidson [5], Evaluation seems to provide a strategic procedure as it envisages what comes after the collection of data and the value judgment " only evaluation can tell us 'So what?"

\section{Types of Assessment}

The role of assessment in the learning process seems basic and fundamental since according to Pelligrino, Chudowsky, and Glaser [6], It provides feedback to students, educators, parents, policymakers, and the public about the effectiveness of educational services. Two main types of assessment are identified: Summative and formative assessment.

Formative assessment (Latin Formare: to shape/ to mold/ to make): According to Sawyer [7], it takes place during the course of teaching and is used essentially to feedback into teaching and learning. Consequently, FA is an assessment for learning. Formative assessment is rather anonymous and is almost never graded. Its aim is to provide faculty with information on what, how much, and how well students are learning.
Summative assessment (Latin summa: sum/ total): Includes tests and other graded evaluations. According to Sawyer [7 p.106], summative assessment an assessment which takes place at the end of a term or course and is used to provide information about how much students have learned and how well a course has worked. Eventually, Summative assessment normally leads to an award of qualifications: grades, diplomas, and certificates. Therefore, SA is basically an assessment of learning. Therefore, the main purpose of SA is to grade or judge or appraise the students' performance and progress through exams, quizzes, tests worksheets and other formats of graded assignments.

We have tried to focus in our present study on the that last type of assessment which is summative assessment since it seems to represent a decisive stage in the students' learning career and the one which has received much debate and arguments among the university students; the testee and the teachers; the tester as well.

\section{Current Assessment Related Key Issues}

Because of being so delicate and decisive in the students learning life career, many key concept emerge to interweave with the idea of testing. Indeed, when we assign a value we produce an impact on the student's behaviour and attitude who is supposed to be the primary client of all assessment. Hence, assessment should be designed to improve performance must ensure that the primary client for the information is well served as well. Nevertheless, there still some serious challenges that can devalue of the assessment set objectives in particular and the teaching-learning process as a whole.

\subsection{Focus on the Answers' Correctness}

One important key feature of a well-designed test or any other type of exam is that which gives more emphasis and seeks the student's ability to extend his/her ideas rather than the correctness of the given answers. However, one can sometimes encounter types of tests where the assessor seeks exact well-definite answers sometimes just for the sake of facilitating the correction task later. Hence, this will eventually have a negative effect of the students' performance since much of his/her abilities of creating meaning and extending ideas will be inhibited. This key feature is intensified by the new trend of questioning where set tests tend to include standardized short-tests of targeted clear direct answers such as multiple choice questions for instance. With regard to that type of questions, students are not tested on the way they use, extend, or criticize "knowledge" but on their readiness to generate a superficially correct response on cue. Indeed, the willingness to save time and labour by the teacher when designing such type of tests has played a negative role on the real aim of testing that of exploring the students learning potentialities. 


\subsection{Lack of Tester and Student Relationship}

The importance of the teacher-student relationship is has often a matter of discussion for current research. Such a relationship is evaluated through academic indicators such as test scores, classroom engagement, and interest in learning. With regard to test scores, the distance between the assessor and the students is growing more and more due to the fact that the designed tests tend to suit more the teachers own pace, interests and way of conception to the tests objectives and, thus, the testing formats. Yet, the students' interests and even their own conception of a beneficial testing should be taken into consideration before the setting of any type of test or exam's exams. The current exams' methods unfortunately, prevent the student from questioning the tester about the questions, the methods, or the results. Besides, by our own philosophy of testing that has been harmfully limited to a mere score or grade that is supposed to measure the students' progress and learning we are putting much threat and pressure on the students' psychological state. The other role of the assessor is to help the testee to avoid all sorts of test's anxiety and threat before seeking all other objectives from his testing.

\subsection{More Scores Less Feedback}

Talking about the teacher-students' relationship in the testing process will lead us to talk about the notion of respect to the first client of testing; the student. Using the word "respect" when talking about tests, exams, grades, and the like may seem like an odd word but it can the appropriate word for a new conception and rethinking of the traditional habits of testing. While being involved in any type of assessment, the assessor can either respect or disrespect the student by his /her behaviour and attitudes to the student's feedback to the target test or exam questions. One good sign of respect, for instance, is allowing to all to the students to explain themselves when we think that they have erred or when we do not understand their answers ( a fact that is commonly and socially accepted in our relationship with people). Moreover, it is disrespectful to give a one shot test that carry no more than a mere score without any mentioned helpful feedback from the part of the teacher. One important role of the teacher is to sustain the students in the learning process. A good sign of sustainment to give ample opportunity for students to practise, refine and master a task that we wish them to do and certify the efficacy that comes from the cycles of model: practice, feedback and refine. Yet, the one shot test is to deprive the students from such a fruitful opportunity. After all, we should be fully aware as teachers that our students have a right to ask for our justification about our point of view to each time they get the chance to receive our assessment to their class performance. It is time to stop considering the assessment task as a mere scrutiny that can only provide grades as clarified Foucault's [8] words "Our modern testing systems are built upon an ancient human urge to perpetuate a marking and classification" to move to the level of making from it an important step of adjusting students' performance and learning practices.

\subsection{Errors and Mistakes' Treatment}

One other important element that needs the teacher's care and consciousness when being involved in the assessment task is the ability to hold a fair attitude to distinguish between the student's committed mistakes and errors. We are all convinced that an error is the result of some sort of ignorance of the correct form of the language usage. However, a mistake is generally is the outcome of carelessness or forgetfulness of such correct form. Let our assessments therefore routinely encourage students to distinguish between what they do and do not know with conviction. Let us, therefore design scoring papers that can carry empathy to the students' committed errors which are the result of honest admission of ignorance or confusion and at the same time heavily penalize all sorts of feigned control over already taught language forms. As a matter of fact, let us give a try, for instance, for students to write a paper in which they critique the previous one they wrote. By doing that, it's the student's responses that are becoming our first matter and not his or her errors. Errors have always existed and will always exist as long as we are learning. Thus, the teacher's main challenge is help students discover their areas of weakness and strength by implementing more in their errors. We should be aware as teachers that we are leading the students through a long up and down path that would finally lead the students to growth and progress.

\section{Method of Data Collection and Analysis}

Our study is based on an online survey questionnaire of about 15 close ended (three MCQ and 12 graded questions) questions that addressed a group of twenty one LMD students with the aim to depict the students' own evaluation, opinions, attitudes and expectations of the current LMD assessment methods and tools. The selected sample randomly included students from first, second and third year level. The students were invited to tell about their opinions and major expectations of the newly set LMD criteria of testing and evaluation at the end of the questionnaire. The questionnaire was used since it is capable of collecting large amount of large amount of factual and behavioural information that is readily processible; [9]

The collected data is clearly exposed in the following tables:

Table 1. Students' Knowledge about the criteria of Evaluation in the LMD system.

\begin{tabular}{lll}
\hline $\begin{array}{l}\text { A. How much are you knowledgeable } \\
\text { on the new set criteria of evaluation in } \\
\text { the LMD system? }\end{array}$ & Responses & Percentage \\
\hline Well-informed & 7 & $33.3 \%$ \\
rather informed & 11 & $52.4 \%$ \\
very little informed & 3 & $14.3 \%$ \\
\hline
\end{tabular}




\section{students'knowledge about the criteria of evaluation in the LMD system}
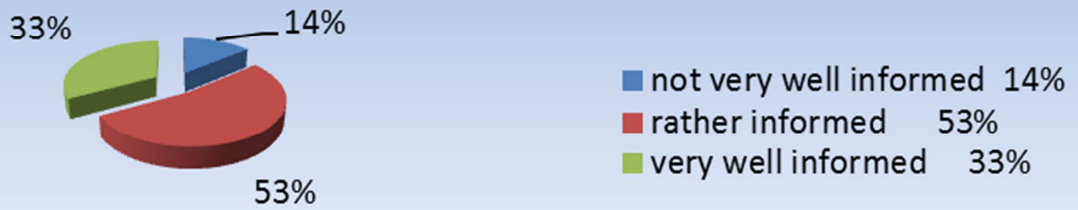

Figure 1. Students' Knowledge about the criteria of Evaluation in the LMD system.

B. How far are you satisfied with those criteria of evaluation in the LMD system?

Table 2. The students' Evaluation to the Criteria of Evaluation in the LMD System.

\begin{tabular}{lll}
\hline & Responses & Percentage \\
\hline Very satisfied & 0 & $0.0 \%$ \\
Satisfied & 16 & $76.2 \%$ \\
Dissatisfied & 5 & $23.8 \%$ \\
\hline
\end{tabular}

\section{the students' evaluation to the criteria of evaluation in the LMD} system

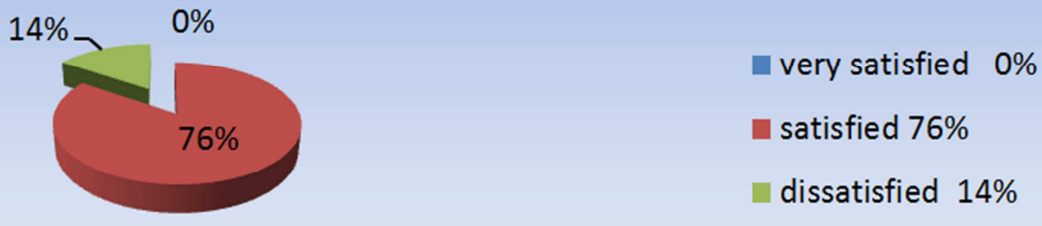

Figure 2. The students' Evaluation to the Criteria of Evaluation in the LMD System.

C. Which assessment method do you prefer to test your performance?

Table 3. The students' Favourite Assessment Method.

\begin{tabular}{lll}
\hline & Responses & Percentage \\
\hline Sit down exams & 4 & $19.0 \%$ \\
course work ( TD) assignments & 3 & $14.3 \%$ \\
the combination of both & 14 & $66.7 \%$ \\
\hline
\end{tabular}

\section{the students' favourite assessment method}
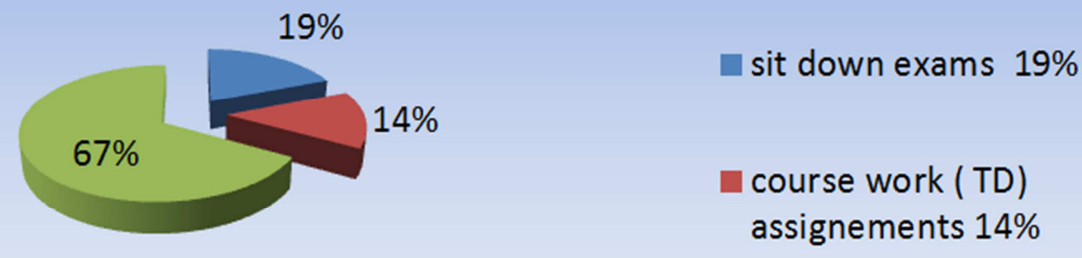

Figure 3. The students' Favourite Assessment Method.

D. Please decide whether you fully disagree or agree with each statement. (Please rate from "strongly disagree" to "strongly agree). 
Table 4. Students' Attitudes to the different Assessment Criteria.

\begin{tabular}{|c|c|c|c|c|c|}
\hline & 1 & 2 & 3 & 4 & 5 \\
\hline 1-The tests given focus much more on the correctness of answers to generic questions & $0.00 \%$ & $15.00 \%$ & $25.00 \%$ & $60.00 \%$ & $0.00 \%$ \\
\hline 2-The tests focus much more on your ability to develop and extend ideas & $0.00 \%$ & $19.05 \%$ & $9.52 \%$ & $47.62 \%$ & $23.81 \%$ \\
\hline 3-The scores given tell you more about your current level and progress & $0.00 \%$ & $14.29 \%$ & $33.33 \%$ & $42.86 \%$ & $9.52 \%$ \\
\hline 5-tests set with precision of scoring set limits to discover your personal intellectual resources & $0.00 \%$ & $22.22 \%$ & $16.67 \%$ & $44.44 \%$ & $16.67 \%$ \\
\hline 6-the tests set suit much more the test maker ( teacher) & $9.52 \%$ & $38.10 \%$ & $33.33 \%$ & $19.05 \%$ & $0.00 \%$ \\
\hline 7-the tests set suit much more the test taker ( student) & $0.00 \%$ & $19.05 \%$ & $23.81 \%$ & $42.86 \%$ & $14.29 \%$ \\
\hline 9-The tests correction provide helpful feedback to my answers & $9.52 \%$ & $9.52 \%$ & $4.76 \%$ & $33.33 \%$ & $42.86 \%$ \\
\hline $\begin{array}{l}\text { 10-As examinee, I want to question the teacher about the questions, the methods, the objectives } \\
\text { and the results }\end{array}$ & $0.00 \%$ & $14.29 \%$ & $19.05 \%$ & $33.33 \%$ & $33.33 \%$ \\
\hline 11- As examinee, I want to be respected by the tester & $4.76 \%$ & $4.76 \%$ & $9.52 \%$ & $9.52 \%$ & $57.14 \%$ \\
\hline $\begin{array}{l}\text { 12-An alternative method (testing during learning)to the one shot test can improve the efficacy } \\
\text { that comes from cycles of model, practice, feedback and refine }\end{array}$ & $5.00 \%$ & $10.00 \%$ & $10.00 \%$ & $25.00 \%$ & $40.00 \%$ \\
\hline
\end{tabular}

1-strongly disagree 2-disagree 3-neither agree or disagree 4-agree 5- strongly agree

What is pretty encouraging is that there is quite a big number of students $(52 \%)$ who are rather informed of the LMD system. By being informed, we mean the knowledge shared among the students about the LMD evaluation criteria. Another important and apparent fact is the satisfaction of large number of students to the new system of evaluation that is based on the combination of the sitdown exams and course work (TD) assignments. Besides, a surface view of the results depicted in the above table would clearly denote a prominent number of students' views affirm that more and more selected tests' questions focus on the correctness of their answers (MCQ and other direct questions are a good instance of that). ertainly much focus on the questions' correctness rather that generic questions' pattern would set limits to the students to discover their own potentialities in the extension of ideas and their latent capacities in the different topics' analysis. Accordingly, the students seem to trust to a far extent the scores they get in their tests and exams since a good number of them (42\%) confirm that such given scores tell truly about their level of progress. More importantly, the students' views converge to one shared tendency to have tests that help them extend and develop their ideas (47\%) as they agree that tests set with a high precision of scoring set to discover their own potentialities and intellectual resources. Besides, a prominent number of students (42\%) admit that the set test and exams suit their level which can be considered as another important gain, too. What is seems rather praise worthy is that an important number of students (42\%) admit that the tests' correction provide helpful feedback to their answers. his denotes that more and more teachers in the LMD system spend extra time in explaining to their students the missed points after any given test with the purpose to provide appropriate remedies for the spotted weaknesses. One other important depicted attitude is related to the fact that many students $(66 \%)$ are not enthusiastic to get informed about the teacher's own selected objectives and methods while he or she wants to set a particular test or exam. This may be owed to the fact that students still believe that the setting of test' questions and their relevant components are typically legitimate tester's tasks and, hence, they may consider it as a sign of disrespect to "nibble" in the teacher's privacy. This interpretation is strongly supported by the attitude of the students when more than $57 \%$ expressed their disagreement to the question of whether they liked to be respected by the teacher while he or she is setting a test for them. Surprisingly, most students' views $(40 \%)$ converged to their satisfaction to the one shot test rather than testing while learning that comes from cycles of model, practice, feedback and refine. One argument to such an attitude is that the one shot test can give an opportunity of sufficient preparation to get ready for it; a chance that they would lack in testing while learning.

Surprisingly, the questioned students showed their praise and satisfaction to the one shot test rather than the alternative method of testing (testing during learning) that can improve the efficacy that comes from cycles of model, practice, feedback and refine. Some students' comments also went for the idea that some teachers' test questions took side to the learning by heart rather than improving the students' abilities of analysis and topic development and extension. In a similar pattern of comments, other students affirmed their wish to have questions that would cover parts of the teacher's lesson explanation and not only what was dictated and written in class. After the data collection, the discussion and analysis of the questionnaire's results, we aimed to give some other students' comments with regard to their own assessment to the LMD system.

\section{Major Students' Comments on the Current LMD System Assessment}

The following are some of the major depicted students' comments o and expectations of the assessments' exams, grades, tests under the LMD system:

Student (A): “.. ersonally I believe, that the assessments' exams, grades, and tests under the LMD system is highly associated and vehemently depend on teachers. In other words, some teachers tests aim to develop the ability of extending ideas, improving and refining the skill of the 
academic and scientific analysis within learners. In this case, the grades can be considered as the correct, precise, and accurate criterion that can tell the learners about their actual level. By way of contrast; there is a host of teachers that their tests depend much more on the ability of learning by heart, and memorizing the giving information. In which, the grades are no longer a beacon that guides the learners and tells their true actual level. The bottom line is, learning process as whole (receiving data, making tests, evaluation) is done with the help of both teachers and students especially in the LMD system, we hope for the creation of teachers who can work on the critical skills of the learners."

Student (B): "I find exams and tests the value that examine our capacities and feedbacks of students. and the grades evaluate their answers. I wish the tests will be much more about what the teachers explained during the courses and not about what students have written on their notebooks. and the extra information given by the student should be taken as a plus to his grade."

Student (C): "We lack assessments in TDs under the LMD system because teachers are much more eager to complete the syllabus than assessing the students. Students are obliged to work hard when there are often an assessments so, it is necessary in TDs in particular. Grades do not always reflect our real levels, but rather reflect how much the student prepared for the test. Teachers' correction do not give an effective enough feedback, but only the mark the students get. Some teachers correct with giving a mark that s/he sees it is appropriate for you production especially when it comes to writing essays and paragraphs, they rather should show for the students their mistakes not to be repeated again and again.

The exam grades tend to be logical in such a way."

Student (D): "well everything is perfect, concerning the exams, grades or tests under the LMD system. the nature of tests and exams suit all students regarding to their level and $i$ really liked the idea of credits, it $s$ very helpful. BUT what I don't like in this system is the programs, in fact I didn't feel that there is a huge difference between the classical system and this one, well I don't know how the teacher choose his own program but we approximately learn the same things that the classical students have learned, this is one thing. the second thing is the atmosphere inside the class room in fact the rooms are well equipped but there is a DARK SIDE which is the sum of students, as we know under the LMD system the room should contain at least 20 student and not exceed 35."

With regards to the above students' views, very interesting remarks can be depicted concerning the current assessment in the LMD system. One clear view for instance blames teaches who set tests that tend to put much emphasis on the students' learning by heart and plainly claims that the tests' grades lose their value and truthfulness when they attributed to students 'answer sheets that are fully the results of learning by heart questions. In fact, such questions may be better suit the aim of the students' memory testing but not the degree of the ideas' extension and development. Another interesting view went for the importance of suggesting questions that would cover some of the teacher' $\mathrm{s}$ lesson explanation and not what just on ideas that were dictated and written in class. It is clear that this view supports the previous one in the sense that both of them seek some sort of questions that respect their intellectual interests and the degree of their thoughtfulness. It was another interesting view that one which stated clearly that the teacher's correction provided no feedback beside the given grade. He or she then insisted that the teacher should give more importance to tell the students about their real mistakes and help do some self-correction in order not to commit the same mistakes again and it is only by doing so that the grades can have a certain value. The last view expressed its satisfaction and praise to the idea of credits which is, according to him or her, is very helpful. Then he or she tries to depict some of the negative aspects of the teaching atmosphere as a whole by pointing out to the big number of students in class not before mentioning that there clear difference between the classical system and the LMD system syllabus, programmes and lessons.

It is clear that there still some of the questioned students who don't have a full dark view on the assessment process in LMD system and admit that there are some gains under this new system such as the option of credits for instance. However much talk was about the teacher's own methods of testing, questions' selection and qualitative feedback correction. The teacher is asked to set question that could test students' amount of thoughtfulness and not only test their memory capacities. Furthermore, he or she should set test that enable students to extend and develop ideas and let them discover their latent potentialities in the analysis and discussion of the different topics. Most importantly, the teacher should give more importance to provide helpful feedback to his or her students' answers. One other effective way of testing that teachers can try in their class is testing during learning. This can give chance to students to take profits of the advantages comes from cycles of model, practice, feedback and refine.

\section{Conclusion}

Assessment remains an essential step in the teaching process and in the student's learning life career and for a better learning there appears to be some assessment principles that need to be respected. In this respect, the students' interests shall be paramount and assessment shall be planned and implemented in ways which maximize benefits for students, while minimizing any negative effects on them. Furthermore,. The primary purpose of assessment shall be to provide information which can be used to identify strengths and to guide improvement. Moreover, Careful consideration should be given to the motivational effects of assessment and evaluation practices and self assessment should be considered as the appropriate starting point. Most importantly, Emphasis should be given to identifying and reporting educational progress and growth, rather than to comparisons of individuals or schools. 


\section{References}

[1] Grant, P. W a (1993). Assessing Student Performance: Exploring the Purpose and the Limits of Testing, $1^{\text {st }}$ ed., Jossey-bass publishers, Sanfrancisco.

[2] Brown, H. D. (2007). Teachingby Principles: An Interactive Approach to Language Pedagogy. Pearson Education.

[3] Brown, S and Knight, P. Assessing Learners in Higher Education. (1994). In Brown, G, Bull, J \& Pendlebury, M. Assessing student learning in higher Education. (1997). USA. Routledge.

[4] Lynch, B. K. (1996). Language program evaluation. Cambridge: Cambridge University Press.

[5] Davidson, E. J. (2005). Evaluation Methodology Basics. New park, CA: Sage Publications, Inc.

[6] Pelligrino, Chudowsky, \& Glaser. (2001). knowing what Students Know: The Science and Design of education assessment. Washington, D. C.: National.

[7] Sawyer, D. B. a (2004). Fundamental Aspects of Interpreter Education. Philadelphia, PA: John Benjamins North America p. 106.

[8] Foucault, M. Discipline and Punish (New York: Vintage Books, 1979), pp. 184-185. Translation Copyright Q 1977 by Alan Sheridan.

[9] Dörnyei, Z (2007) Research Methods Applied Linguistics, Oxford University Press. 